\title{
Click Nucleic Acid-DNA Binding Behavior: Dependence on Length, Sequence, and Ionic Strength
}

Heidi R. Culver ${ }^{\mathrm{a}}$, Jasmine Sinha ${ }^{\mathrm{a}}$, Tania R. Prieto ${ }^{\mathrm{a}}$, Christopher Calo ${ }^{\mathrm{a}}$, Benjamin D. Fairbanks ${ }^{\mathrm{a}}$, Christopher N. Bowman ${ }^{\mathrm{a}, \mathrm{b}, \mathrm{c} *}$

${ }^{a}$ Department of Chemical and Biological Engineering, bepartment of Chemistry and Biochemistry, and ${ }^{\mathrm{c}}$ Materials Science and Engineering Program, University of Colorado Boulder, Boulder, CO, 80309, United States

$\underline{\text { Table of contents: }}$

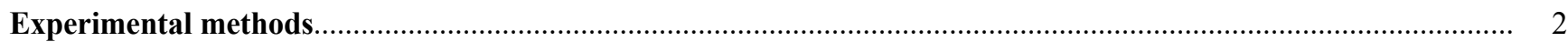

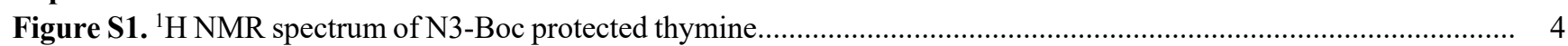

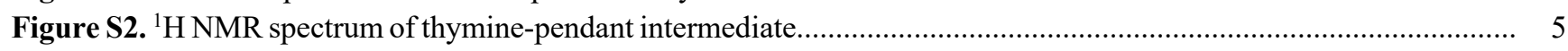

Figure S3. ${ }^{1} \mathrm{H}$ NMR spectrum of thioacetyl protected N3-Boc-protected thymine monomer............................................ 6

Figure S4. SEC chromatograms showing effect of polymerization solvent on CNA molecular weight.............................. 7

Figure S5. CD spectra of oligo(T) CNA-(dA) 20 showing helical structure .................................................................... 7

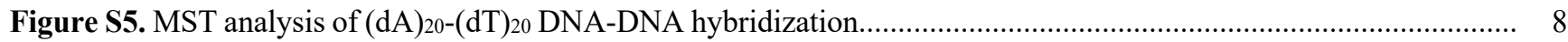

Table S1. SEC characterization of HPLC isolated oligo(T) fractions........................................................................ 8 


\section{Experimental methods}

\section{Materials}

5-methyl uracil (thymine), 2-chloroethylaminee hydrochloride, di-tert-butyl decarbonate (Boc anhydride), and dimethylsulfoxide (DMSO, $\geq 99 \%$ ) were purchased from Chem-Impex. 4-dimethylaminopyridine, diethylaniline, chloroacetyl chloride, potassium thioacetate, 1,8-diazabicyclo[5.4.0] undec-7-ene (DBU), anhydrous toluene, anhydrous dichloromethane (DCM), and anhydrous dimethylformamide (DMF) were purchased from Sigma Aldrich. Sodium hydroxide, magnesium sulfate, methanol and sodium iodide were purchased from Fisher Scientific. Silica gel was purchased from Silicycle. HyClone HyPure molecular biology grade water was purchased from GE Healthcare Life Sciences. Saline sodium citrate (SSC) buffer (20X) was purchased from IBI Scientific and diluted with molecular biology grade water for use in binding experiments. HPLC-purified, Cy5-labeled DNA oligonucleotides were purchased from Integrated DNA Technologies. All other chemicals were of reagent grade and used without further purification.

\section{Instrumentation}

NMR spectra were recorded on a Bruker Advance-III 400 spectrometer (400 MHz). Size exclusion chromatography (SEC) was performed using a TOSOH EcoSEC equipped with UV and refractive index detectors. SEC was run with the column oven at $50^{\circ} \mathrm{C}$ with DMSO as the mobile phase. HPLC separation of oligo(T) CNA was performed on an Agilent 1200 series equipped with a G1315 Diode Array Detector. CNA concentrations were determined using a DeNovix DS11 FX+ spectrophotometer. Microscale thermophoresis measurements (MST) were performed on a Nanotemper Monolith NT.115 instrument using the red filter sets and standard (untreated) capillaries.

\section{Synthesis of MonoBoc-protected thymine monomer}

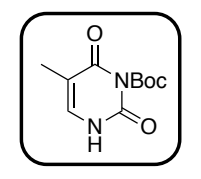

To a solution of $21.6 \mathrm{gm}(99 \mathrm{mmol}) \mathrm{Boc}_{2} \mathrm{O}$ in $200 \mathrm{~mL}$ of anhydrous DCM was added $5 \mathrm{gm}$ ( $\left.39 \mathrm{mmol}\right)$ of thymine followed by the addition of $0.48 \mathrm{gm}(3.9 \mathrm{mmol})$ of DMAP. The reaction mixture was stirred overnight at room temperature under $\mathrm{N}_{2}$ atmosphere. The reaction mixture was then concentrated at reduced pressure to achieve a pale white solid. The crude residue was used for next step without purification. To a solution of $10 \mathrm{gm}$ of crude product in $100 \mathrm{~mL}$ of $\mathrm{DCM} / \mathrm{MeOH}(9 / 1)$ was added $60 \% \mathrm{w} / \mathrm{w} \mathrm{SiO} 2$ and the resultant mixture was subjected to reflux at $60^{\circ} \mathrm{C}$ for $1 \mathrm{hr}$. The reaction mixture was then concentrated at reduced pressure. The resulting crude residue was purified by flash column to afford pure products as white solids. Yield: $88 \%,{ }^{1} \mathrm{H} \mathrm{NMR}\left(\mathrm{CDCl}_{3}, \delta \mathrm{ppm}\right): 10.10(\mathrm{~s}, 1 \mathrm{H}), 7.06$ $(\mathrm{d}, \mathrm{J}=5.63 \mathrm{~Hz}, 1 \mathrm{H}), 1.92$ (s, 3H), 1.61 (s, 9H); ${ }^{13} \mathrm{C} \mathrm{NMR}\left(\mathrm{CDCl}_{3}, \delta \mathrm{ppm}\right): 161.86,150.86,147.85,135.92,110.60,87.04,27.48,12.34$. HRMS (ESI $\left.{ }^{+}\right) \mathrm{m} / \mathrm{z}$ calculated for $\mathrm{C}_{10} \mathrm{H}_{14} \mathrm{~N}_{2} \mathrm{O}_{4} \mathrm{Na}[\mathrm{M}+\mathrm{Na}]^{+}: 249.0851$, found: 249.0853 .

\section{Synthesis of Boc-Protected Thymine CNA 2G Monomer}

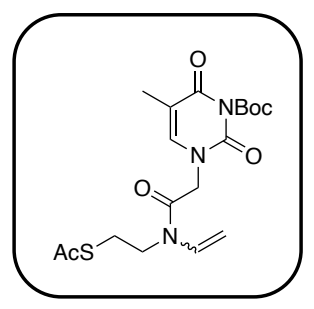

The dichloride intermediate was synthesized as originally reported (Han 2018). To a solution of $3.7 \mathrm{gm}$ (16.5 mmol) of monobocprotected thymine monomer in $90 \mathrm{~mL}$ of anhydrous DCM was added $3 \mathrm{gm}$ (16.5 mmol) of dichloride intermediate, followed by the addition of $2.7 \mathrm{gm}(18 \mathrm{mmol})$ of DBU. The reaction mixture was stirred for $1 \mathrm{~h}$ at room temperature under N2 atmosphere. The organic layer was then washed with $100 \mathrm{~mL}$ of water twice. The combined organic layer was dried over Na2SO4 and concentrated at reduced pressure to achieve a yellow viscous liquid. The crude residue was purified by column chromatography (silica gel, hexane/ethyl acetate 40:60) to obtain pale yellow viscous liquid. Yield: 50\%; 1H NMR (CDCl3, $\delta \mathrm{ppm}): 7.38(\mathrm{dd}, 0.3 \mathrm{H}, \mathrm{J}=9.0,16.0 \mathrm{~Hz}), 6.96(\mathrm{~s}, 1 \mathrm{H}), 6.70$ $(\mathrm{dd}, 0.7 \mathrm{H}, \mathrm{J}=9.0,16.0 \mathrm{~Hz}), 4.86-4.69(\mathrm{~m}, 3 \mathrm{H}), 4.68(\mathrm{~d}, 1 \mathrm{H}), 4.02(\mathrm{t}, 2 \mathrm{H}, \mathrm{J}=7.0 \mathrm{~Hz}), 3.81(\mathrm{t}, 1 \mathrm{H}, \mathrm{J}=7.0 \mathrm{~Hz}), 3.65(\mathrm{t}, 1 \mathrm{H}, \mathrm{J}=7.0 \mathrm{~Hz})$, $1.97(\mathrm{~s}, 3 \mathrm{H}), 1.62(\mathrm{~s}, 9 \mathrm{H})$. 
The obtained yellow viscous boc-protected thymine intermediate $(3 \mathrm{gm}, 8 \mathrm{mmol})$ was then dissolved in $80 \mathrm{~mL}$ of anhydrous DMF followed by the addition of $3.7 \mathrm{gm}(32 \mathrm{mmol})$ of potassium thioacetate and catalytic amount of sodium iodide. The reaction mixture was stirred overnight at $50^{\circ} \mathrm{C}$ under $\mathrm{N}_{2}$ atmosphere. The reaction mixture was then concentrated at reduced pressure to achieve a yellow viscous liquid which was then diluted with DCM. The organic layer was then washed with $100 \mathrm{~mL}$ of water and then $50 \mathrm{~mL}$ of brine. The combined organic layer was dried over $\mathrm{Na}_{2} \mathrm{SO}_{4}$ and concentrated at reduced pressure to achieve a yellow viscous liquid. The crude residue was purified by column chromatography (silica gel, hexane/ethyl acetate 30:70) to obtain pale yellow viscous liquid. The hence obtained pale yellow viscous liquid was then dissolved in diethyl ether and kept for recrystallization which resulted in desired product as white solid (thymine CNA $2 \mathrm{G}$ monomer with acetyl functionality). Yield: $70 \% ;{ }^{1} \mathrm{H} \mathrm{NMR}\left(\mathrm{CDCl}_{3}, \delta \mathrm{ppm}\right): 7.35(\mathrm{dd}, 0.30 \mathrm{H}, \mathrm{J}=9.0$, $16.0 \mathrm{~Hz}), 6.97(\mathrm{~s}, 1 \mathrm{H}), 6.65(\mathrm{dd}, 0.70 \mathrm{H}, \mathrm{J}=9.0,16.0 \mathrm{~Hz}), 5.09(\mathrm{~m}, 0.72 \mathrm{H}), 4.81(\mathrm{~m}, 1.28 \mathrm{H}), 4.77(\mathrm{~s}, 1 \mathrm{H}), 4.69-4.61(\mathrm{~m}, 1 \mathrm{H}), 3.87-3.65$ $(\mathrm{m}, 2 \mathrm{H}), 3.11(\mathrm{t}, 0.60 \mathrm{H}, \mathrm{J}=8 \mathrm{~Hz}), 3.04(\mathrm{t}, 1.40 \mathrm{H}, \mathrm{J}=8.0 \mathrm{~Hz}), 2.43(\mathrm{~s}, 0.90 \mathrm{H}), 2.37(\mathrm{~s}, 2.10 \mathrm{H}), 1.96(\mathrm{~s}, 3 \mathrm{H}), 1.62(\mathrm{~s}, 9 \mathrm{H})$.

\section{Polymerization and purification of oligo(T) CNA}

Thioacetyl deprotection was achieved by adding $5 \mathrm{~N} \mathrm{NaOH}$ to an equivalent volume of $0.5 \mathrm{M}$ solution of thioacetyl-protected thymine CNA 2G monomer in methanol purged with $\mathrm{N}_{2}$, and was stirred at room temperature for 20 minutes. HEPES buffer (250 mM, pH 7.5) was added to maintain a pH around 7.5 upon neutralization with $3 \mathrm{~N} \mathrm{HCl}$. DCM was added and the organic layer was extracted several times and dried over $\mathrm{Na}_{2} \mathrm{SO}_{4}$ before concentrating at reduced pressure to achieve a white solid. The obtained thiol functionalized thymine CNA 2G monomer, obtained as a white solid, was then dissolved in anhydrous DMF (10 wt \% of monomer in DMF) followed by the addition of $1 \mathrm{wt} \%$ of Irgacure 819 initiator. The solution was then irradiated using a mercury-lamp (Acticure 4000) with a 400-500 $\mathrm{nm}$ bandgap filter at light intensity of $20 \mathrm{~mW} / \mathrm{cm}^{2}$ for 20 minutes at ambient temperature. DMF was removed under reduced pressure to obtain Boc-protected oligo(T) CNA.

Boc deprotection of oligo(T) CNA was achieved via addition of concentrated hydrochloric acid. After 5 minutes, HEPES buffer (250 $\mathrm{mM}, \mathrm{pH} 7.5$ ) was added to maintain a $\mathrm{pH}$ around 7.5 upon neutralization with $5 \mathrm{~N} \mathrm{NaOH}$. After neutralization, the precipitated polymer was collected via centrifugation $(10,000 \mathrm{~g}, 5 \mathrm{~min})$ and washed with water 5-10 times with water and 2 times with acetone to remove salts from the deprotection, as well as any cyclized monomer. The desired Boc-deprotected oligo(T) CNA was obtained as a white solid in 30-50\% yield. CNA molecular weight and polydispersity were estimated based on SEC using standards generated from short, firstgeneration CNA oligomers.

\section{Chromatographic separation of polydisperse oligo(T) CNA}

Separation of oligo(T) CNA was performed on an Agilent 1200 series HPLC using a SunFire Prep C18 OBD column (column dimensions $=30 \times 150 \mathrm{~mm}$ ). The column is packed with $5 \mu \mathrm{m}$ silica with a pore size of $100 \AA$. The system started with pure acetonitrile and was then was equilibrated to $75 / 25$ acetonitrile to methanol before injecting the sample ( $300 \mu \mathrm{L}$ dissolved at $250 \mathrm{mg} / \mathrm{mL}$ in $75 / 25$ acetonitrile/methanol and filtered through a $0.25 \mu \mathrm{m}$ PTFE filter). The flow rate was set to $3.5 \mathrm{~mL} / \mathrm{min}$ and fractions were collected every minute. Data evaluation was done using Agilent ChemStation. CNA molecular weight and polydispersity for each fraction were estimated based on SEC using standards generated from short, first-generation CNA oligomers.

\section{Microscale thermophoresis}

The DNA (5'-(dA)20-3'-Cy5) stock solution $(500 \mathrm{nM})$ was prepared in 0.66X SSC and then diluted 1:5 into aqueous DMSO containing 25-62.5 vol\% DMSO, depending on the experiment. This DNA solution was combined 1:1 with serial dilutions of oligo(T) CNA in $100 \%$ DMSO. The final concentration of the fluorescently labeled DNA was kept constant $(50 \mathrm{nM})$ while the concentration of the nonfluorescent CNA was varied from $410 \mu \mathrm{M}$ to $12.5 \mathrm{nM}$. Concentration was estimated based on UV absorbance measurements using an extinction coefficient for thymine in DMSO of $8000 \mathrm{M}^{-1} \mathrm{~cm}^{-1}$ at $260 \mathrm{~nm}$ and dividing by the number average degree of polymerization. The red light emitting diode (LED) of the MST was used to excite Cy5. Changes in thermophoretic mobility were described by $F_{\text {norm }}$ (the ratio of the fluorescence in the center of the capillary when the infrared laser is on (Fhot) to when the infrared laser is off $\left.\left(\mathrm{F}_{\text {cold }}\right)\right)$. $\mathrm{F}_{\text {norm }}$ was used to calculate the fraction bound according to Equation S1:

(S1) $\theta_{\text {hyb }}=\frac{F_{\text {norm, }[\mathrm{CNA}]}-F_{\text {norm }, \min }}{F_{\text {norm, } \max }-F_{\text {norm }, \min }}$ 
where $\mathrm{F}_{\text {norm,min }}$ and $\mathrm{F}_{\text {norm,max }}$ correspond to the minimum and maximum normalized fluorescence, respectively, and $\mathrm{F}_{\text {norm, [CNA] }}$ corresponds to the normalized fluorescence at a given CNA concentration. Fraction bound was plotted as a function of CNA concentration and fit to a quadratic binding model (Equation 1) in order to determine the apparent dissociation constant (Kapp) at different conditions.

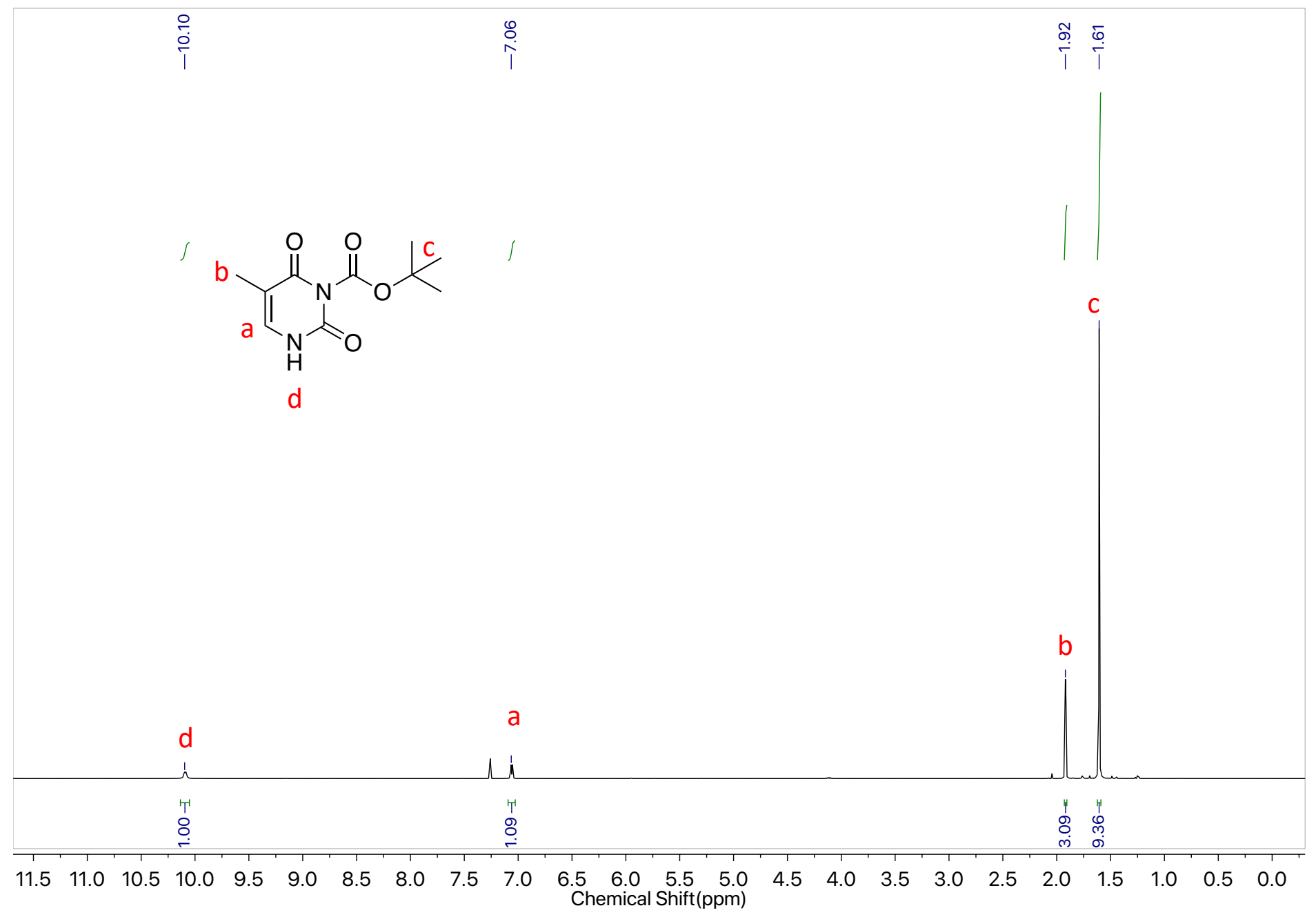

Figure S1. ${ }^{1} \mathrm{H}$ NMR of thymine pendant intermediate. 


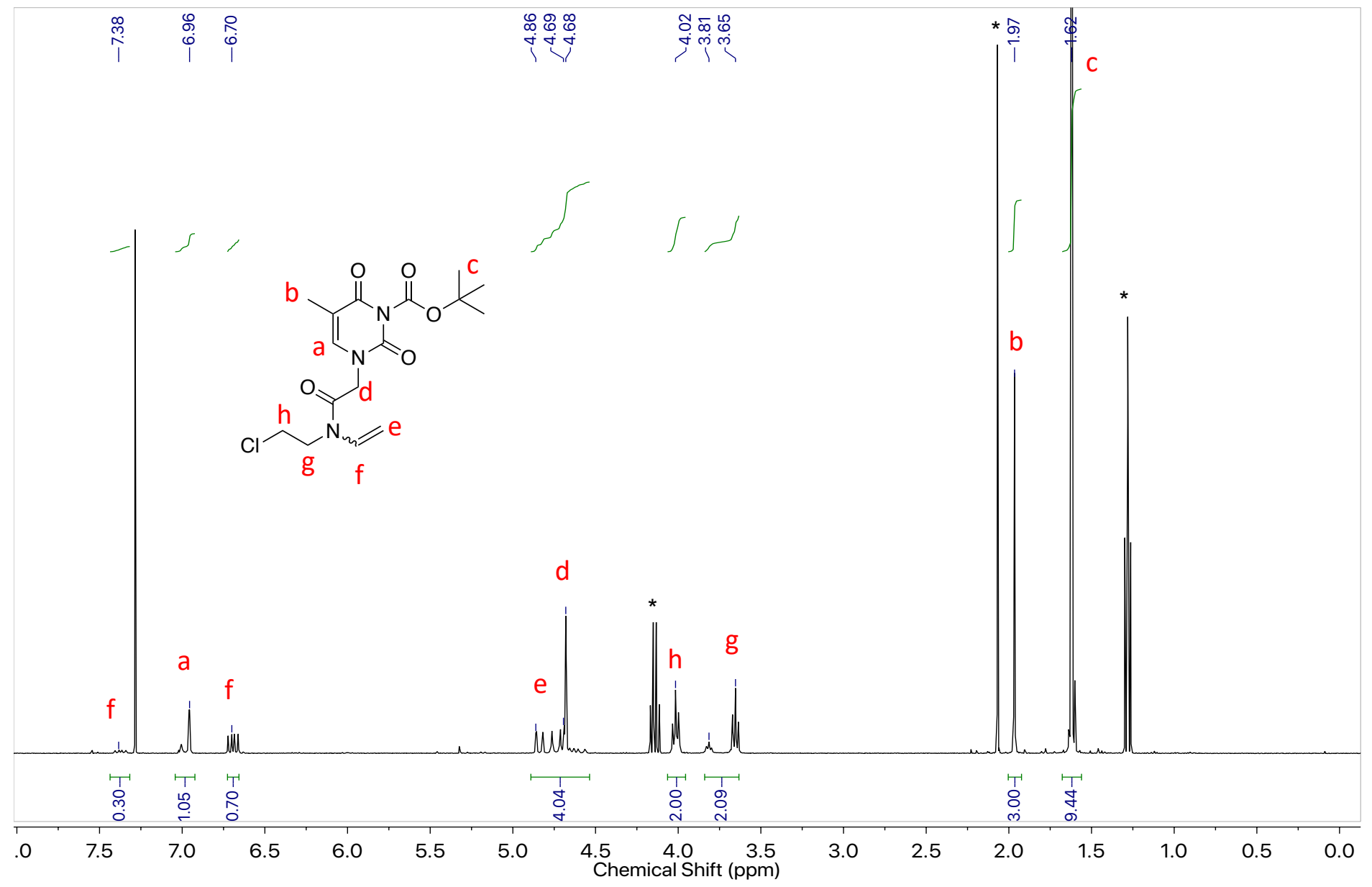

Figure S2. ${ }^{1} \mathrm{H}$ NMR spectrum of thymine-pendant intermediate. (* indicates residual solvent) 


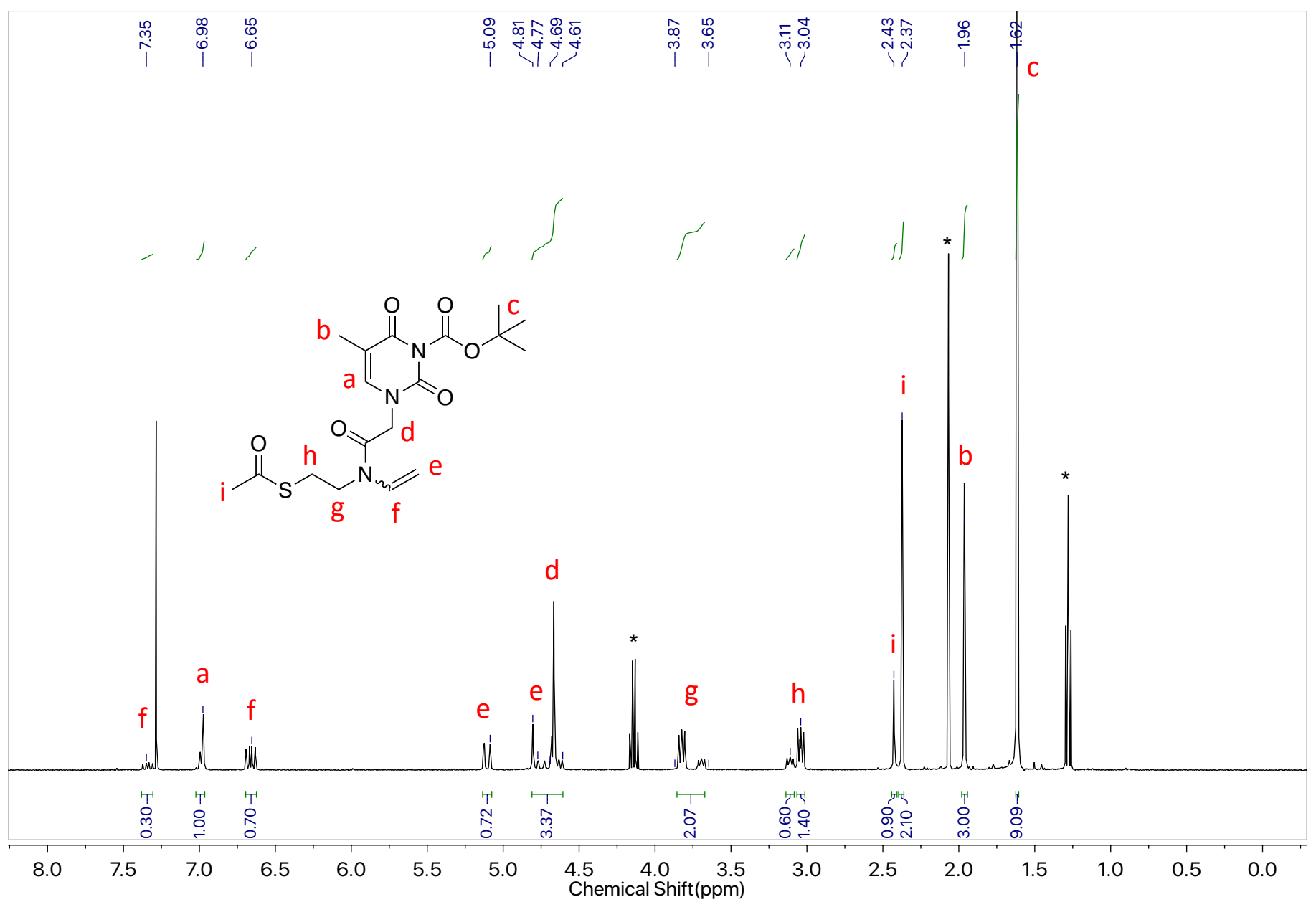

Figure S3. NMR of thioacetyl protected, N3-Boc protected monomer. (* indicates residual solvent) 

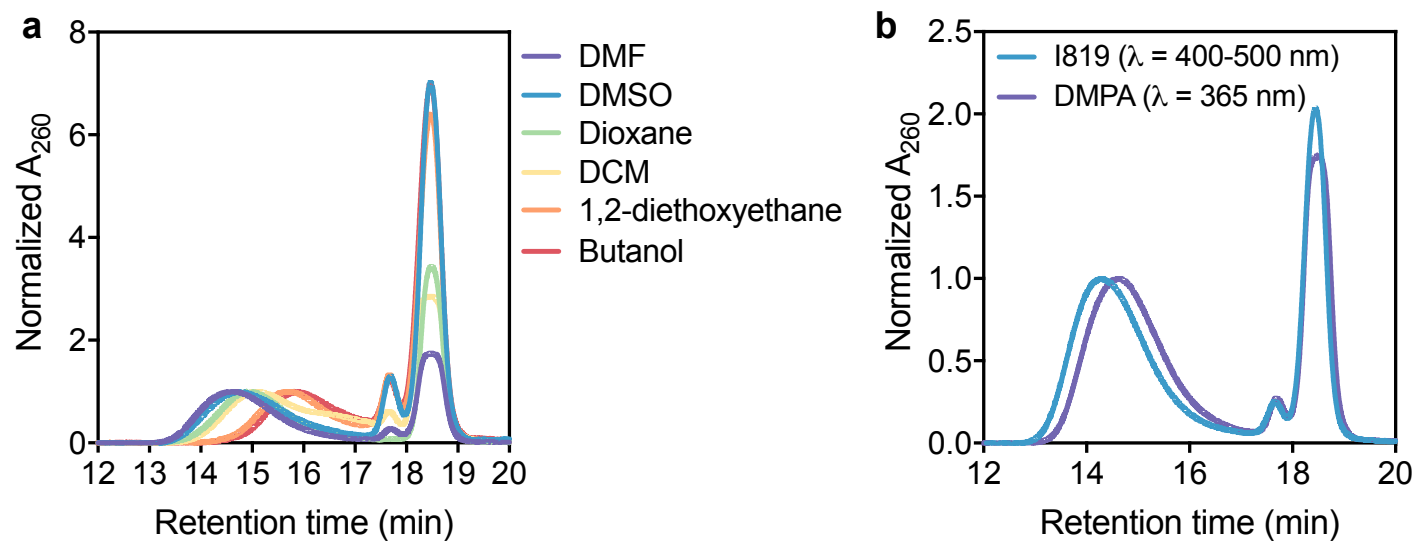

Figure S4. SEC chromatograms showing the effect of solvent and initiator on oligo(T) CNA size distribution. (a)

Polymerization of the Boc-protected monomer in DMF and DMSO, good solvents for both the monomer and polymer, with DMPA as the photoinitiator yielded the highest molecular weight oligo(T) CNAs. (b) Use of Irgacure 819 (I819) as the photoinitator rather than DMPA slightly improved the number average molecular weight of the oligo(T) CNAs, and thus was used as the initiator for all subsequent polymerizations.

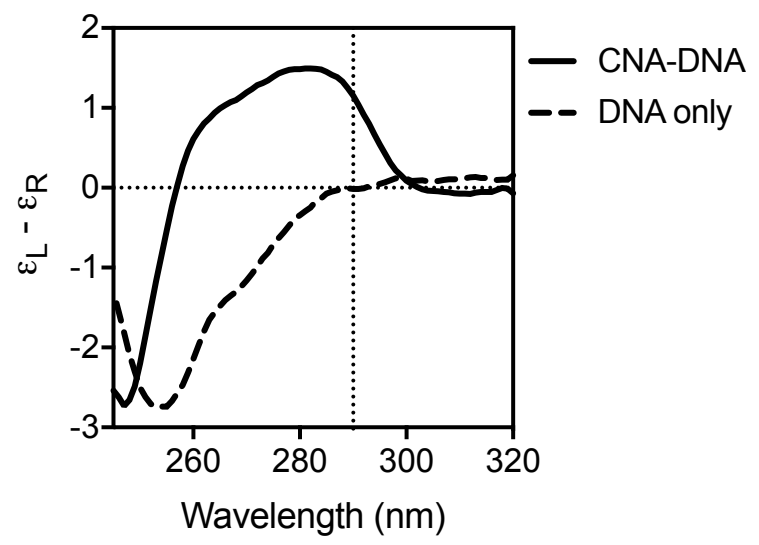

Figure S5. CD spectra of oligo(T) CNA-(dA)20 showing helical structure. CD spectra were recorded in 65 vol\% DMSO for (dA) 20 alone or $(\mathrm{dA})_{20}$ mixed with oligo(T) CNA. Oligo(T) CNA is achiral, so no CD signal would be expected for oligo(T) CNA by itself. As such, the change in CD spectra of (dA)20 upon addition of CNA suggests the CNA-DNA duplex forms a B-form helix akin to DNA duplexes with Watson-Crick base pairing. 


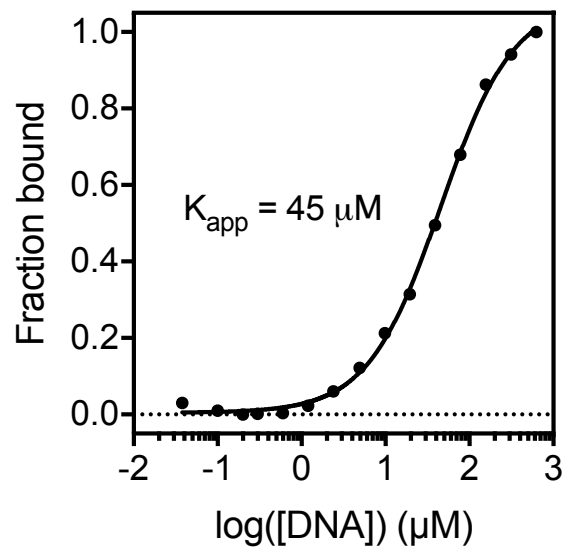

Figure S6. MST analysis of (dA)20-(dT)20 DNA-DNA hybridization. MST measurements were performed in the absence of DMSO with $25 \mathrm{mM} \mathrm{Na}^{+}$. The concentration of Cy5 labeled (dA)20 DNA was kept constant at $50 \mathrm{nM}$ and the concentration of (dT)20 was varied from $625 \mu \mathrm{M}$. Kapp was determined based on fitting to a quadratic binding model (Equation 1).

Table S1. SEC results from HPLC separated CNA oligomers used to test the effect of CNA length on CNA-DNA Kapp. Fractions were collected every $\mathrm{x}$ min at a flow rate of $3.5 \mathrm{~mL} /$ minute. Crude oligo(T-boc) CNA was used for HPLC separation, so later fractions had residual monomer and the yield of the first two fractions was too low to perform MST analysis.

\begin{tabular}{|l|l|l|l|}
\hline Fraction & Mn & DP & PDI \\
\hline 3 & 5700 & 21 & 1.17 \\
\hline 4 & 4900 & 18 & 1.16 \\
\hline 5 & 3400 & 13 & 1.26 \\
\hline 6 & 2700 & 10 & 1.31 \\
\hline 7 & 2200 & 8 & 1.35 \\
\hline 8 & 2000 & 7 & 1.34 \\
\hline
\end{tabular}

